\title{
Comentario Agricultura familiar y pobreza rural, hacia un cambio de paradigma
}

Sergio Ernesto Medina-Cuéllar ${ }^{\mathrm{a}}$ y Marcos Portillo-Vázquez ${ }^{\mathrm{a}}$

DOI: $10.7201 /$ earn.2014.01.11.

\section{Introducción}

En América Latina la agricultura familiar es un tema prioritario, ya que es la fuente de ingresos de una gran cantidad de familias, y desempeña un papel importante en el combate del hambre y la pobreza, mediante la suma de voluntades internacionales, dentro de un marco de esfuerzos para lograr tanto la soberanía alimentaria, como una mejor administración de los recursos naturales.

La designación del 2014 como el Año Internacional de la Agricultura Familiar (AIAF-2014) pone de manifiesto la voluntad política para construir asociaciones más sólidas más allá de los intereses nacionales particulares, en favor de un fin común más noble; el consenso entre los líderes mundiales respecto a los desafíos que el género humano enfrenta a escala global, para mejorar la seguridad alimentaria.

Cuando se instauró este año internacional, con el impulso del Foro Rural Mundial (FRM), también se lograron establecer objetivos concretos, que tal como lo expone el Sr. Álvaro Ramos en su artículo, para alcanzarlos ha de concretarse un cambio de paradigma, en lo que respecta a la conceptualización de la agricultura familiar, la cual se muestra como una solución a la pobreza rural, y no una consecuencia de esta.

\section{Innovar para el desarrollo}

Nuevos paradigmas marcan puntos de inflexión en la búsqueda de medios de vida sostenibles para el género humano. A diferente ritmo e intensidad, los diferentes ámbitos de la vida y las diversas áreas del conocimiento están experimentando cambios derivados de una crisis alimentaria global. En el campo del desarrollo local, nuevos modelos de comportamiento surgen, retomando la importancia del ser humano con la tierra, volviendo un poco a los orígenes del desarrollo de las comunidades humanas, en las que cada núcleo familiar era directamente responsable de la gestión y conservación de la superficie de tierra necesaria para procurar su subsistencia a nivel particular, y en consecuencia, la de su comunidad creando una sinergia colectiva.

\footnotetext{
a Universidad Autónoma Chapingo, México.

E-mail: mportillo49@yahoo.com.mx.
} 
El paradigma clásico de la innovación en el que unos solo producen, otros transfieren y el resto adopta, bajo una lógica puramente mecanicista, está perdiendo su hegemonía ante un paradigma más ético y constructivo para abordar las necesidades y problemas de la raza humana.

Investigadores agrícolas han vuelto a enfocar su atención en las prácticas tradicionales de agricultores en pequeña escala, para rescatar valores culturales ancestrales, que tienen una lógica muy distante del objetivo de ganancia en términos monetarios, y que actualmente retoman vigencia.

La investigación agrícola que emplea procedimientos científicos, últimamente tiende a volver a observar los métodos tradicionales de producción, con propósito de mejorar pero no de sustituir totalmente las prácticas tradicionales, aprovechando la experiencia práctica de los productores en pequeña escala, junto con el conocimiento derivado de la investigación científica.

Para poder incentivar iniciativas de innovación en la producción derivada de la agricultura familiar, desde una perspectiva que reconozca la necesidad de entregar a las familias herramientas metodológicas que les permitan crear nuevas propuestas, bajo sus propios procedimientos para resolver sus necesidades alimenticias en su ámbito particular, lo cual implica que sus ideas se modifiquen y sigan aprendiendo, será necesario tomar en consideración tres aspectos fundamentales:

- El ámbito de desarrollo de las comunidades para la creación e implementación de innovaciones trascendentes.

- La ética económica, como compromiso con el orden moral de la cooperación social del hombre, para satisfacer sus necesidades vitales y culturales, en concordancia con la sustentabilidad de la vida en el entorno de cada territorio en particular.

- La acción recíproca entre las explotaciones familiares, con los diferentes actores del mercado, como estrategia para abrir la puerta a nuevas alternativas de generación y apropiación del conocimiento, considerando su aplicación e implicaciones.

En el proceso de cambio de paradigma que la agricultura familiar ha comenzado a experimentar, con la conciencia de la aproximación de grandes cambios en la gestión de las relaciones entre la sociedad, la ciencia y los avances tecnológicos, la innovación institucional se posiciona antes de la innovación tecnológica, debido a que la segunda modifica la realidad material, mientras que la primera modifica la forma de pensar de la gente que lleva a cabo los cambios materiales, transformando la manera en que interpretan su realidad particular. 


\section{El papel de la innovación institucional}

El género humano está afrontando un cambio de época, una importante transición del significado del progreso antes conceptualizado bajo la imagen de la fábrica industrial, la cual ahora se muestra como símbolo de contaminación y deshumanización de las relaciones sociales, industriales y productivas, por lo que la población está volviendo la mirada hacia los procesos productivos tradicionales.

Con imparcialidad se puede observar que la forma de producir y consumir de la sociedad industrial no está en concordancia con los límites de los ecosistemas de donde provienen las materias primas, generando en consecuencia la vulnerabilidad de los ciudadanos. Los supuestos que establecen la idea de desarrollo de la civilización occidental están perdiendo vigencia tan rápido como los resultados de bienestar que prometía se han visto incumplidos; en consecuencia, los marcos conceptuales que se derivaron de tales supuestos también se encuentran en crisis.

En cada etapa histórica se establece el paradigma de innovación predominante. La actual crisis alimentaria pone de manifiesto una crisis en la innovación para el desarrollo, dentro de la sociedad industrial de la civilización occidental, razón por la cual también sufren las consecuencias de tal incertidumbre las denominadas naciones desarrolladas.

Experiencias que deben rescatarse para la elaboración de políticas públicas son las practicadas por las mujeres en agricultura de auto-consumo, donde generan alimentos obtenidos en mucho menor tiempo para satisfacer oportunamente las necesidades de alimento de la familia, mientras el hombre cultiva productos de cosecha a más largo plazo y que las necesidades de alimento de la familia no pueden esperar. Este modelo es origen y causa de la diversidad de cultivos en una misma unidad productiva minifundista, en la que prevalecen un buen número de prácticas de sustentabilidad del suelo que se pueden rescatar y mejorar.

Esta situación conduce a plantear las preguntas obligadas. ¿Por qué después de décadas de progreso, la humanidad sufre hambre ante un mundo cada vez más vulnerable? ¿Qué alternativas tiene Latinoamérica para enfrentar la desigualdad y el hambre de su gente?

En su artículo el Sr. Ramos explica que las alternativas de solución a estas y otras preguntas relevantes, apuntan hacia la necesidad del Diálogo Político para diseñar mejores políticas públicas, dando lugar a la exploración de sus implicaciones para el desarrollo regional de la agricultura familiar, y el consecuente proceso de innovación social y tecnológica. Es aquí donde se encuentra la clave del proceso innovador necesario. Una razón más para analizar la agricultura familiar es que probablemente las unidades de producción familiar seguirán siendo numerosas y permanecerán por mucho tiempo conviviendo con las prácticas de agricultura comercial en gran escala. Sin el consenso internacional, ante una realidad evidente, poco o nada pueden hacer los esfuerzos aislados. 


\section{Cambios de paradigma en el proceso de innovación}

Bajo el contexto planteado por el Sr. Ramos, en el que la agricultura familiar lejos de ser sinónimo de pobreza, se perfila como alternativa de progreso y bienestar, surgen giros paradigmáticos que van a la par con este cambio de pensamiento.

Entre los múltiples giros de pensamiento que se vislumbran, los nuevos esquemas de producción de la agricultura familiar implican cambiar la forma de innovar predominante en el ámbito del desarrollo territorial, por lo que es primordial transformar el modo en el que los actores sociopolíticos y económicos, conciben la dinámica de esta forma de producción.

Es importante identificar que este medio de vida propicia la conservación de la diversidad genética de las especies vegetales propias de cada ámbito geográfico, lo que constituye un innovador banco viviente de germoplasma. Aunado a su folclore regional particular, la agricultura familiar favorece la preservación de semillas autóctonas, libres de modificaciones genéticas en debate, a la vez que contribuye al rescate, mantenimiento y mejora del medio ecológico, en comparación con las explotaciones agrícolas comerciales.

Fomentar un medio de vida sostenible como la agricultura familiar, representa un cambio de paradigma que implica el cultivo de las relaciones, propósitos y prácticas que originan y dan sustento y sentido a la existencia de las diversas formas de vida, en cada región con su realidad particular.

\section{El compromiso mundial después de 2014}

Al inicio de este artículo, se puntualiza que el AIAF-2014 es un paso firme en beneficio de un consenso mundial, donde la voluntad política trasciende los individualismos nacionales en favor de la población más desfavorecida más allá de cada frontera, de cara a los retos presentes y futuros de los medios de vida sostenibles.

En su artículo el Sr. Ramos hace ver la importancia de la agricultura familiar, y que, para innovar en este medio de vida sostenible, es necesario un giro conceptual en el que esta forma de producción se muestra como un medio de sustento viable. Por lo que tanto, las instituciones del medio rural, como las implicadas en la producción familiar, deberían reflexionar sobre cómo actualizarse con respecto a este cambio de mentalidad.

Amplia gratitud y reconocimiento merecen todas aquellas personas que, en el afán de procurar un mundo mejor para todos, están implicadas de una u otra forma, en el impulso a largo plazo de los objetivos perseguidos en el AIAF-2014. 